\title{
Midkine (MDK) growth factor: a key player in cancer progression and a promising therapeutic target
}

\author{
Panagiota S. Filippou $\mathbb{1}^{1,2} \cdot$ George S. Karagiannis ${ }^{3,4,5} \cdot$ Anastasia Constantinidou ${ }^{6,7,8}$
}

Received: 6 July 2019 / Revised: 15 November 2019 / Accepted: 19 November 2019 / Published online: 4 December 2019

(c) The Author(s), under exclusive licence to Springer Nature Limited 2019

\begin{abstract}
Midkine is a heparin-binding growth factor, originally reported as the product of a retinoic acid-responsive gene during embryogenesis, but currently viewed as a multifaceted factor contributing to both normal tissue homeostasis and disease development. Midkine is abnormally expressed at high levels in various human malignancies and acts as a mediator for the acquisition of critical hallmarks of cancer, including cell growth, survival, metastasis, migration, and angiogenesis. Several studies have investigated the role of midkine as a cancer biomarker for the detection, prognosis, and management of cancer, as well as for monitoring the response to cancer treatment. Moreover, several efforts are also being made to elucidate its underlying mechanisms in therapeutic resistance and immunomodulation within the tumor microenvironment. We hereby summarize the current knowledge on midkine expression and function in cancer development and progression, and highlight its promising potential as a cancer biomarker and as a future therapeutic target in personalized cancer medicine.
\end{abstract}

\section{Introduction}

Midkine (MDK) is a heparin-binding growth factor first discovered as a highly expressed gene during mouse embryogenesis [1]. To date, MDK is viewed as a multifunctional protein and along with pleiotrophin (PTN), they form a structurally unique family of heparin-binding growth factors [2]. MDK is a soluble secreted protein that is highly elevated in various diseases, such as cancer, and therefore it

Panagiota S. Filippou

P.Philippou@tees.ac.uk

1 School of Health \& Life Sciences, Teesside University, Middlesbrough TS1 3BX, UK

2 National Horizons Centre, Teesside University, 38 John Dixon Ln, Darlington DL1 1HG, UK

3 Department of Anatomy and Structural Biology, Albert Einstein College of Medicine, Bronx, NY, USA

4 Integrated Imaging Program, Albert Einstein College of Medicine, Bronx, NY, USA

5 Gruss-Lipper Biophotonics Center, Albert Einstein College of Medicine, Bronx, NY, USA

6 Medical School, University of Cyprus, Nicosia, Cyprus

7 Bank of Cyprus Oncology Centre, Nicosia, Cyprus

8 Cyprus Cancer Research Institute, Nicosia, Cyprus could serve as a valuable disease biomarker [3]. In many types of cancer, MDK has been shown to be overexpressed [3], especially during tumor progression into more advanced stages [4]. Of note, MDK expression in tumors has been determined by blood [5, 6], urinary [7], and tumor analysis [8].

MDK is implicated in various physiological processes such as development, reproduction, and repair thus playing important roles in the pathogenesis of malignant and other diseases [9]. Therefore, this protein is expressed by a variety of cells under physiological and pathological conditions. Under physiological conditions significant MDK expression is observed in the epidermis [10], bronchial epithelium [11], and lymphocytes [12, 13]. Contrarily, in another study, MDK was shown to be expressed in several tumor cell lines, but not in blood-derived normal cells, including monocytes, lymphocytes, or activated $\mathrm{T}$ lymphocytes [14]. Consistent with its role during mouse embryogenesis, MDK is expressed in embryonic stem cells and its role in their survival has been well documented [15]. In particular, MDK is intensely expressed in the midgestation stage and from the mode of its distribution, has been suggested to play roles in neurogenesis, epithelial-mesenchymal interactions and mesoderm remodeling [16, 17]. Moreover, the mode of MDK location is consistent with its multiple roles in neurogenesis. MDK is strongly expressed in the basal layer of the cerebral cortex, which is rich in neural precursor cells, 
including neural stem cells and also in radical glial processes, which are extensive neutral stem cells derived processes [18].

In spite of the roles of MDK in development mentioned above, MDK-deficient mice are born without major defects [19]. However, mice deficient in both genes MDK and PTN are born smaller in size, and about $50 \%$ of them die before 4 weeks (see in [9]), suggesting that MDK and PTN potentially compensate for each other during embryogenesis [9]. Furthermore, mice deficient in MDK or PTN exhibit a moderate auditory deficit, while mice deficient in both present with more severe phenotype [20]. Moreover, mice deficient in MDK exhibit normal phenotypes in overall neural functions [19], although more in-depth analysis revealed deficits in specific neural functions [21].

Of note, MDK is strongly expressed by the majority of tumor cells in human malignant tumors $[9,22]$ and this will be the highlighted topic of the current review. As mentioned, MDK functions as a cytokine and growth factor with complex biological functions, and is implicated in a variety of (patho)physiological processes [4]. MDK is involved in the acquisition of multiple hallmarks of cancer: it promotes tumor cell proliferation, transformation, and epithelial-tomesenchymal (EMT) transition; [22-24] it has angiogenic [25], mitogenic [26], antiapoptotic [27], and antitumor immunity [28] roles, and it has also been involved in chemoresistance [29]. The wide expression of MDK in many tumors, its causative involvement in cancer development and progression, as well as its potential role as a cancer biomarker, are currently under investigation, because of the many potential translational applications, as will be outlined below.

In this review, we offer a detailed insight on the functions and the molecular and biological significance of MDK in cancer. Specifically, we provide an updated and critical viewpoint on the involvement of MDK in cancer progression and response to chemotherapy, as well as its emerging roles in antitumor immunity and inflammation. Furthermore, we highlight and explore the significance of this protein as a tentative tumor biomarker in different types of cancer, as well as its potential as a drug therapeutic target.

\section{Genomic and protein domain organization of MDK}

The human MDK gene, located on 11q11.2 chromosome, encodes a 15.5-kDa protein rich in basic and cysteine amino acids (UniProtKB - P21741 (MK_HUMAN)) [30-32].

In the promoter region of MDK, there are functional binding sites for retinoic acid receptor [33] and a hypoxia responsive element, possibly involved in the increased expression of MDK in various tumors [34]. Hypoxia induces MDK expression through the binding of the HIF-1a to a hypoxia responsive element in MDK promoter [34]. There is also a binding site for the product of Wilms' tumor suppressor gene [35] for MDK upregulation in Wilm's tumor cells [36]. Contrarily, MDK was shown to be downregulated by cortisol in fetal lung development via a glucocorticoid receptor action [37].

The MDK human gene consists of four coding exons. Due to the differential splicing and differences in the transcription initiation site, there are seven isoforms in the MDK mRNA. Two isoforms are generated by skipping a coding exon and yield truncated MDK (tMDK) (Fig. 1a). A tMDK variant derived from mRNA without the second coding exon is tumor-specific and might be of diagnostic value [9]. Different other tMDK variants have also been reported in the literature. For instance, a truncated MDK variant (tMDKC) resulting from a deletion of part of exon 3 plus most of exon 4, encodes a putative 62 amino acid product [38]. Another variant (tMDK) has also been identified in Wilms's tumor tissues [39] and in a variety of metastatic gastrointestinal cancers. It remains to be elucidated whether such truncated variants play any role in a physiological, besides neoplastic, context. Moreover, an isoform with two extended amino acids at the N-terminal is present in MDK (the first two MDK residues (valine (V) and alanine (A)), called the 'VA-MDK' [40] (Fig. 1a). Therefore these two forms (the conventional MDK and the 'VA-MDK') (Fig. 1a) may occur simultaneously in vivo [40] and may have a different biological significance.

Mutations in MDK gene were not found in high frequency; a mutation was only found in lung cancer, cervical cancer, and malignant melanoma patients respectively (http://www.oasis-genomics.org/, TCGA). Moreover, only three missense mutation types of unknown significance identified in lung cancer (lung squamous cell carcinoma and lung adenocarcinoma) and one nonsense mutation in lung adenocarcinoma (cBioPortal for Cancer Genomics).

MDK protein contains a signal peptide for secretion (aa 1-20) and the main protein chain (aa 21-143) with two distinct domains ( $\mathrm{N}$-terminal and $\mathrm{C}$-terminal domain) flanked by intra-domain with disulfide bridges [41] (Fig. 1a). MDK and PTN share 50\% sequence homology with cysteine and tryptophan residues being conserved in humans [9]. Among the two conserved MDK domains, the $\mathrm{C}$-domain has been considered to play more important role in MDK function, exerting neurite-promoting activity [22]. Moreover, two heparin-binding sites are present in the Cdomain of human MDK [22]. The N-domain appears to be important for the stability of MDK as the C-terminal half of MDK is more susceptible to chymotrypsin digestion [42], involved in MDK dimerization [22]. Overall, further studies of the expression and function of MDK variants in health and disease are clearly warranted, and the relative 
a

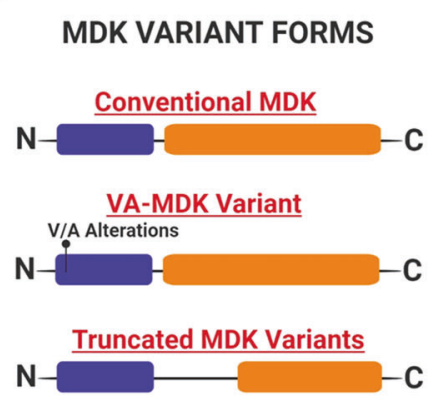

MDK PROTEIN ORGANIZATION

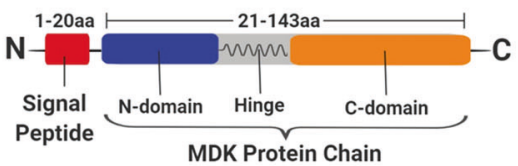

b

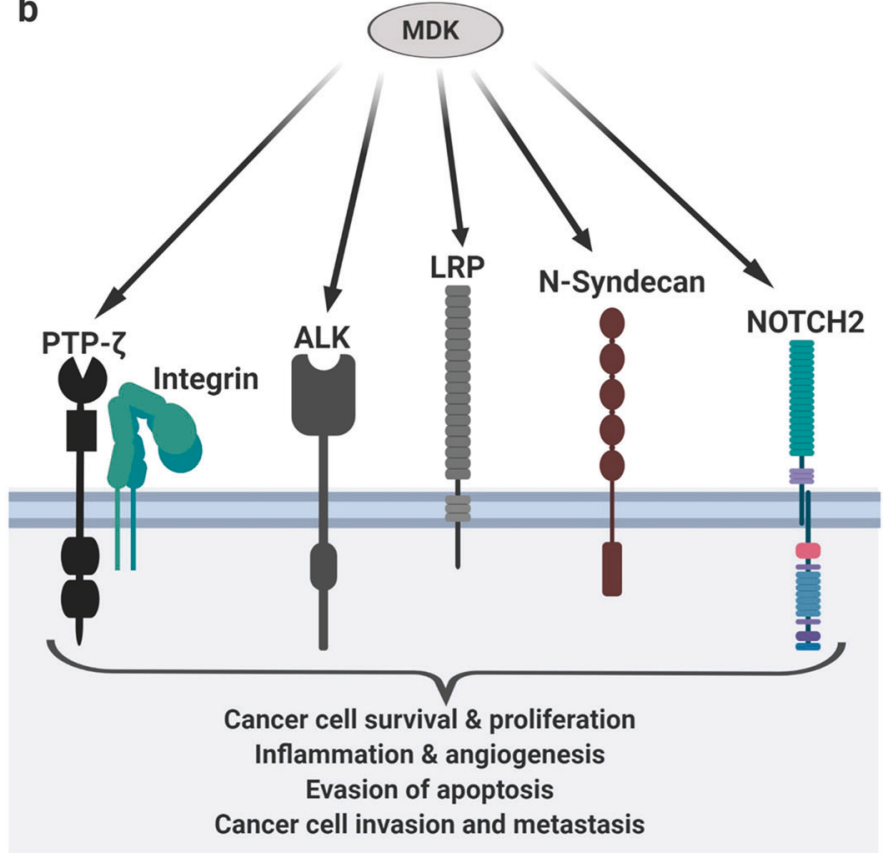

Fig. 1 Structural domain organization and candidate receptors of MDK protein. a MDK isoforms and splice variants. The conventional and 'VA-MDK' variants differing in the N-terminal sequence in two amino acids [(the first two MDK residues (valine(V) and alanine(A)], as well as truncated MDK forms, are displayed in a comparative manner. The protein domain organization of MDK according to Uniprot Database [UniProtKB - P21741 (MK_HUMAN)], is shown in the bottom half of the panel. MDK is a secreted protein of $15.5 \mathrm{kDa}$ containing a signal peptide for secretion (aa 1-20) and the main protein chain (aa 21-143), composed of two domains (N-Domain and C-Domain) held together

expression levels of full-length vs. MDK variants (for both gene and protein levels) (Fig. 1a) might prove to be diagnostically useful.

\section{Implications of MDK in the hallmarks of cancer}

MDK is a protein that initiates signaling through liganddependent receptor activation for a biological response [43]. To date, there have been key advances made on elucidating the functional MDK-mediated mechanisms, including diverse receptors and complicated intracellular signaling pathways. The glycosaminoglycan (GAG)-recognizing activity of MDK is important for this mechanism of action. For this reason, proteoglycans including receptor-like protein tyrosine phosphatase- $\zeta$ (PTP- $\zeta$ ) [44], syndecans [17], and glypican-2 [45], demonstrate a strong affinity for MDK (Fig. 1b). Other proteins, such as low-density lipoprotein receptor-related protein (LRP) [46], $\alpha 4 \beta 1$-integrin, and $\alpha 6 \beta 1$-integrin [47] also serve as putative MDK receptors, which, together with PTP- $\zeta$ form a receptor complex for MDK binding (Fig. 1b). In general, the interactions of by disulfide linkages. The $\mathrm{C}$-terminal located domain is responsible for midkine activity and the $\mathrm{N}$-terminal domain is required for dimerization [2]. b MDK interactions with different plasma membrane receptors, including syndecans, integrins, protein tyrosine phosphatase $\zeta$ (PTP $)$, anaplastic lymphoma kinase (ALK), low-density lipoprotein (LDL)-receptor-related protein (LRP), and Notch2 receptor. All (or some) of these receptors could function as a multimolecular complex coordinated to transduce the MDK signal into the cell by different signaling pathways, thus regulating different cancer-related phenotypes

MDK with the above mentioned receptors or receptor complexes promote cancer cell growth, migration, metastasis, and angiogenesis [23] via the activation of downstream signaling cascades [44, 46] (Fig. 1b).

As already explained, MDK is a growth factor overexpressed in various human malignancies [43, 48], and the downstream signaling events may be linked to a vast plethora of phenotypic characteristics leading to cancer development and progression [25, 49-51] (Fig. 1b). In this chapter, we describe the involvement of MDK in cancerrelated signaling from the viewpoint of the well-described hallmarks of cancer, as described by Hanahan and Weinberg [52] and indicated briefly as an illustration in Fig. 2.

\section{MDK-mediated proliferation/growth signaling, and apoptosis evasion}

Recent studies demonstrated that MDK binds to heparan sulfate and chondroitin sulfate and activates several signaling pathways contributing to cell growth and proliferation [9] via downstream signaling systems such as the Src family kinases and the tyrosine phosphorylation of PI3kinase and MAP kinases [46, 51] (Fig. 2a). 

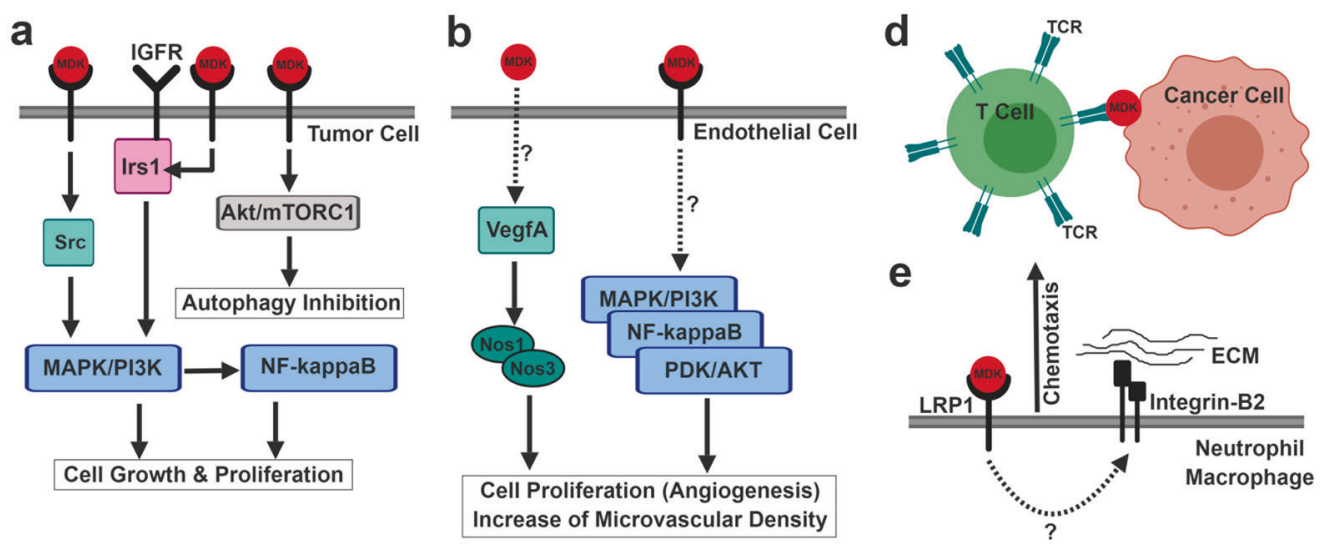

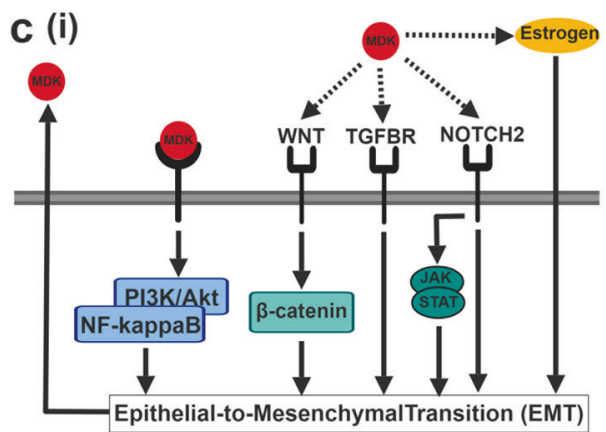

(ii)

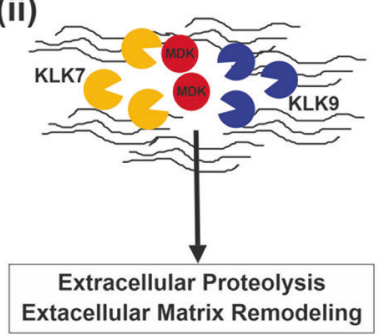

(iii)

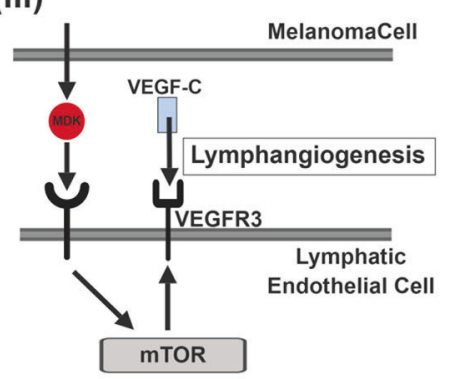

Fig. 2 Implications of MDK in the hallmarks of cancer. a MDKmediated proliferation/growth signaling through conventional intracellular circuitries and pathways (Src/MAPK/PI3K; akt/mTORC1/NFkappaB), b MDK involvement in angiogenesis and microvascular density through conventional cancer-associated angiogenic pathways, c MDK-mediated regulation of cancer cell invasion and metastasis via at least three disparate mechanisms: (i) epithelial-to-mesenchymal (EMT) transition, (ii) extracellular proteolytic relationships with

Moreover, it was demonstrated that the resistance of glioma cells to tetrahydrocannabinol (THC) relies on the MDK-mediated stimulation of anaplastic lymphoma kinase (ALK), making the cells resistant to autophagy-mediated cell death in vitro and in vivo $[53,54]$. In particular MDK, modulates p8/TRB3 expression as well as the activity of the Akt/mTORC1 axis, via the ALK receptor, to prevent the autophagy-mediated cell death by THC cannabinoids [55] (Fig. 2a). In vivo MDK silencing or ALK pharmacological inhibition sensitizes cannabinoid-resistant tumors to THC antitumoral action [55], suggesting that MDK/ALK axis could be an efficient target for glioma therapies. Previous reports also suggested that ALK is included in the receptor complex of MDK along with LRP and integrins [9, 54]. In specific, after activation of the receptor complex by MDK, ALK phosphorylates the insulin receptor substrate-1, and activates MAP kinase and PI3-kinase leading to transcriptional activation of nuclear factor kappa-light chain-enhancer of activated B cells (NF-kB) [54] (Fig. 2a). Taken together, MDK acts through diverse downstream signaling pathways, including, but not limited to, the Src and NF-кB kallikrein-related peptidases (KLKs) in the tumor microenvironment, (iii) MDK-driven neolymphangiogenesis via mTOR signaling pathway activation and increased VEGFR 3 expression, $\mathbf{d}$ MDK involvement in antitumor immunity. MDK-specific cytotoxic T lymphocytes can lyse tumor cells. e MDK-dependent immune cell chemotaxis: Neutrophil/ macrophage adhesion and chemotaxis are mediated via an LRP1/ $\beta 2$ integrin signaling interplay that facilitates their trafficking during cancer-associated acute inflammation

to elicit protumoral responses in many cancer types. Interestingly, MDK may also be implicated in survival pathways in hematopoietic malignancies. Foremost, MDK enhances the survival of mature B cells and the suppression of MDKdependent survival pathway might be considered for treatment of B cell malignancies [56].

\section{MDK-mediated angiogenesis}

Of note, the tumor growth-promoting activity of MDK is also partially due to its ability to promote tumor angiogenesis. MDK, apart from a heparin-binding cytokine or a cancer cell growth factor, is also a potent proangiogenic factor [57, 58]. Enhanced tumor growth after subcutaneous injection of MDK into nude mice was in part associated with increased microvessel density, indicating enhanced proliferation of endothelial cells within the tumor [25] (Fig. 2b). Interestingly, high MDK expression was localized in tumor endothelial cells of human neural tumor tissues, suggesting that endothelial cells also can represent the source of MDK during tumor angiogenesis [59]. In 
addition, conditioned media of cancer cells, artificially induced to overexpress MDK has been shown to induce angiogenesis by promoting proliferation of endothelial cells in vitro [58]. Antisense oligonucleotides against MDK inhibited growth of endothelial cells in vitro and tumorinduced angiogenesis in a chorioallantoic membrane (CAM) assay and tumor vascularization in vivo [60]. Mechanistically, MDK seems to control plasma bioavailability of vascular endothelial growth factor-A, which in turn, is related to the expression of neuronal nitric oxide synthase (Nos1) and endothelial Nos (Nos3) in endothelial cells, and eventually angiogenesis [61] (Fig. 2b).

Although speculative, there is now a compelling line of evidence suggesting that MDK could be involved in hypoxia-mediated tumor angiogenesis: (i) hypoxia induces MDK expression through the binding of HIF-1a to a hypoxia responsive element on the MDK promoter [34], (ii) MDK was also shown to be implicated in hypoxia-induced angiogenesis in nonneoplastic contexts such as ischemia of adult normal tissues [62], (iii) hypoxia increases MDK protein levels in human polymorphonuclear neutrophils $(\mathrm{PMN})$, monocytes, and human umbilical vein endothelial cells [62] and (iv) as already mentioned, the tumor growthpromoting activity of MDK has been found to be due to its ability to promote tumor angiogenesis [58]. The precise mechanistic underpinnings remain to be elucidated.

\section{MDK-mediated cancer invasion and metastasis}

MDK has been proposed to mediate metastasis by its combined mitogenic, proinflammatory, and angiogenic functions [4, 63, 64]. Of note, MDK has been linked to EMT $[65,66]$ (Fig. 2c, i) and has been described to interact with various protein members of the TGF- $\beta$ pathway in vitro [65], a central mediator pathway for EMT [67], thus leading to increased migration of cancer cells in vitro and in vivo [66]. In addition, MDK was described to mediate cell survival and growth mainly through phosphatidylinositol 3-kinase (PI3K) and extracellular signal-regulated kinase (ERK) signaling [68, 69]. However, the expression of cell-cell and cell-matrix adhesion molecules ICAM-1, Ecadherin, periostin, and MDK was not significantly linked to metastatic disease in pancreatic ductal adenocarcinomas (PDACs) cells [65]. Furthermore, estrogen enhanced MDK expression in accordance with an increase of EMT, whereas knockdown of MDK blocked EMT under estrogen stimulation in lung adenocarcinoma, indicating a pivotal role of MDK in progression of estrogen-regulated EMT [70]. After ligand-receptor interactions of PTP $\zeta$ with MDK, tyrosine phosphorylation was increased in cytoplasmic signaling molecules, such as $\beta$-catenin $[71,72]$. Dephosphorylation of $\beta$-catenin is a critical step in the canonical Wnt signaling. In normal osteoblasts, MDK has been shown to inhibit osteoblast proliferation by interfering in Wnt signaling via inhibition of the $\mathrm{PTP} \zeta$-mediated dephosphorylation of $\beta$-catenin [71]. In glioma development, the Wnt/ $\beta$-catenin/ MDK molecular network as control mechanism was further revealed. It was found that Wnt3a administration or transfection of a constitutively activated $\beta$-catenin promoted MDK expression in glioma cells [73]. Furthermore, a TCF/ LEF binding site was identified, with which beta-catenin interacts, on the proximal promoter region of MDK gene [73].

In another study, an interaction between the Notch2 receptor and MDK (Fig. 2c, i), in PDAC cells activated Notch signaling, induced EMT upregulated NF-kB, and increased chemoresistance in a downstream sequence [74]. The interaction of Notch 2 and MDK was observed in vitro, with the treatment of Notch2-positive PDAC cells with soluble MDK resulting in Notch2 activation and linked to upregulation of Notch downstream targets (Hes-1 and NFkB/RelA) [74]. Similarly, it was also demonstrated that MDK binds to the Notch2 receptor in HaCaT, thus activating Notch2 signaling and leading to an MDK-induced cross talk of Notch $2 / \mathrm{Jak} 2 / \mathrm{Stat} 3$ signaling pathways that regulate cell plasticity and motility contributing to EMT, as well as to later stages of tumorigenesis [75].

Proteolytic enzyme networks may also participate in MDK-induced metastasis [76, 77] (Fig. 2c, ii). Interestingly, kallikrein-related peptidases (KLKs), the largest family of extracellular serine peptidases known to-date [78], may play a leading role in the regulation of the cell-biological programs, facilitating cancer progression, particularly through extracellular hydrolysis of crucial mediators such as cell-cell adhesion proteins, membrane-bound proteins and receptors, cytokines and growth factors, ECM proteins, as well as other KLKs [78]. MDK was identified as a key substrate for the two chymotrypsin KLKs (KLK7 and KLK9) [76, 77] upon specific cleavage, suggesting a potential role of the KLK7/9-MDK axis in cancer progression and metastasis, especially in tumors with aberrant deregulation of KLK7/9 expression [79, 80]. Future studies should investigate the exact roles of extracellular proteolytic networks in MDK cleavage regulation and MDK-driven metastasis.

A prometastatic role of MDK in melanoma progression was based on its link to neolymphangiogenesis via the mTOR signaling pathway [81] (Fig. 2c, iii). MDK binds heparan sulfate and lymphatic endothelial cells, thus activating mTOR signaling to increase the expression of VEGFR3, through which major lymphangiogenic signals are transduced [81]. These signals stimulate the systemic lymphangiogenesis and tumor cell transmigration through the lymphatic endothelium in premetastatic sites (Fig. 2c, iii). As expected, the silencing of MDK decreased lymphangiogenesis and metastasis in lymph nodes and lungs, 
while MDK overexpression caused the opposite effect in immunodeficient nu/nu mice [81].

\section{MDK-mediated antitumor immunity and inflammatory response}

\section{Involvement of MDK in antitumor immunity}

The emerging appreciation of the MDK function in the immune system has been assessed, by sculpting myeloid cell phenotype and driving immune cell chemotaxis [14] (Fig. 2d). In addition, it has been shown that in vitro stimulation of $\mathrm{CD}^{+} \mathrm{T}$ cells collected from HLA-A2 healthy donors and immunization of HLA-A2 transgenic mice, identified two $\mathrm{CD}^{+} \mathrm{T}$ cell epitopes, which demonstrate that MDK-specific cytotoxic T lymphocytes can lyse tumor cells [14] (Fig. 2d). One of these CD8 ${ }^{+} \mathrm{T}$ cell epitopes resides in the signal peptide, as described previously for other secreted tumor antigens [82], suggesting that MDK could be a novel candidate for cancer vaccine development. Moreover, the capacity of MDK to prime $\mathrm{CD} 4^{+} \mathrm{T}$ lymphocytes in humans and localized several $\mathrm{CD}^{+}{ }^{+} \mathrm{T}$ cell epitopes of MDKrestricted to different HLA-DR molecules was also identified [28]. Two $\mathrm{CD}^{+} \mathrm{T}$ cell epitopes, overlapping MDK signal peptide but differing in their processing outcome in tumor cells, were responsible for a large proportion of the $\mathrm{T}$ cell response [28].

\section{MDK-mediated tumor promoting inflammation}

MDK is one of the growth factors that modulate inflammation [83], in part due to presenting similar properties with antibacterial proteins triggering the activation of the innate immune system [84]. MDK expression is strongly induced during inflammatory processes [85], leading to increased angiogenesis. Neutrophils, which also play a role in angiogenesis [86], have a designated role in MDK-mediated inflammation. MDK seems to support the PMN adhesion by promoting high affinity of $\beta 2$-integrins, thereby facilitating PMN trafficking during acute inflammation (Fig. 2e). The suppression/blocking of low-density lipoprotein receptorrelated protein 1 (LRP1) suggested that it may act as a receptor for MDK on PMNs [87] (Fig. 2e). Besides neutrophils, MDK also regulates macrophage chemotaxis [85] and MDK-deficient mice displayed lower neutrophil and macrophage numbers in a model of early-stage of fracture healing [88]. The important role for the proinflammatory cytokines MDK and IL-6 in the response to fracture in estrogen-deficient mice was also assessed [89], and demonstrated increased MDK levels after fracture in mice and female fracture patients after menopause. Given the above, the role of MDK in the neutrophil and macrophagemediated inflammatory responses in cancer need to be confirmed and elucidated. In this context, the potential pharmacological targeting of MDK as a potential antiinflammatory therapy should also be assessed.

\section{MDK as a diagnostic and prognostic cancer biomarker}

MDK overexpression at the gene and the protein level within the tumor is a typical feature of cancer and has been reported for several different cancer types [90-93]. As a plasma-secreted protein, MDK has also been found increased in the blood and urine of patients with malignant tumors $[94,95]$. Although there are studies showing lack of association between MDK plasma levels and diagnostic accuracy or prognostic significance (i.e., endometrial cancer) [96], MDK has been reported as a potential diagnostic and prognostic cancer biomarker associated with poor survival $[97,98]$. Because it is not cancer-specific, but related to the tumorigenic process as described above, MDK may be considered as multicancer biomarker. Since there is an urgent need for the discovery of novel tumor biomarkers, here, we detail the potential of MDK as a cancer biomarker, and its role in prognosis and/or diagnosis in certain types of cancer (Table 1).

\section{Pancreatic cancer}

Pancreatic cancer is one of the most aggressive human malignant cancers associated with rapid progression and poor prognosis [99]. Insufficient diagnostic tools and therapeutic options for PDAC still substantiate its ranking as fourth leading cause of cancer-related death. Therefore, a better understanding of newly identified and cancer-specific key molecules that could serve as novel diagnostic and prognostic tumor markers for PDAC are needed. Foremost, MDK mRNA was found to be overexpressed in pancreatic cancer tissues compared with normal tissues, suggesting that MDK is an early disturbed molecule in the course of pancreatic neoplasmatogenesis [100]. Importantly, serum MDK concentrations were found significantly elevated in patients with PDAC compared with healthy individuals [101], suggesting a potential role of MDK as a diagnostic marker for PDAC.

\section{Lung cancer}

Lung cancer is the leading cause of cancer-related mortality worldwide [102]. The incidence of non-small cell lung cancer (NSCLC), a major form of lung cancer, has increased in the past several decades. Early stage detection of lung cancer is a key aspect that may offer more treatment options and a greater chance of survival to patients. MDK is 
Table 1 The role of MDK as a diagnostic and prognostic biomarker in different types of cancer

\begin{tabular}{|c|c|c|c|c|c|c|c|}
\hline & \multirow[t]{2}{*}{ Cancer type } & \multicolumn{3}{|c|}{$\begin{array}{l}\text { MDK overexpression } \\
\text { (mRNA/protein) }\end{array}$} & \multirow[t]{2}{*}{ Diagnostic } & \multirow[t]{2}{*}{ Prognostic } & \multirow[t]{2}{*}{ Reference } \\
\hline & & Blood & Tissue & $\overline{\text { Urine }}$ & & & \\
\hline \multirow[t]{9}{*}{ MDK/Cancer type } & Pancreatic & + & + & - & + & - & {$[100,101]$} \\
\hline & Lung & + & + & + & + & + & {$[3,103,104]$} \\
\hline & Bladder & - & + & + & + & + & [106-109] \\
\hline & Liver & + & + & - & + & - & [112-115] \\
\hline & Melanoma & - & + & - & - & + & {$[81,116]$} \\
\hline & Brain & + & + & - & + & + & [118-120] \\
\hline & Esophageal & + & + & - & - & + & [122-125] \\
\hline & Breast & + & + & - & + & + & {$[127,128]$} \\
\hline & Ovarian & + & + & - & + & - & {$[130]$} \\
\hline
\end{tabular}

one of the six-biomarker blood test for the detection of early stage lung cancer at risk populations [3]. A significant association was observed between overexpressed MDK (mRNA and protein levels) with malignant status and poor prognosis in NSCLC patients [103]. MDK levels were found to be useful, minimally invasive biomarkers for NSCLC detection and prognosis [104].

\section{Bladder cancer}

Bladder cancer (BCa) is the most common malignancy of the urinary tract in the elderly population and the sixth most common cancer in men worldwide [105]. Although a great effort was performed to investigate putative urinary biomarkers suitable for the noninvasive diagnosis of $\mathrm{BCa}$, a routine application of these tests is not recommended for the primary detection of $\mathrm{BCa}$ [106]. MDK protein expression in $\mathrm{BCa}$ and its correlation with a poor outcome in invasive bladder carcinomas has been reported [107], and increased MDK protein levels in urine specimens from $\mathrm{BCa}$ patients [7, 108, 109] was demonstrated. Importantly, the correlation between MDK protein concentration in urine and disease progression in terms of tumor stage and grade has been previously investigated [108]. MDK protein showed a substantial elevation in the urine of patients, although not in the urine of those with early-stage low-grade tumors [108]. In another study, increased MDK levels were normalized to urinary creatinine, indicating that MDK may potentially be suitable marker for the identification of patients with high risk $\mathrm{BCa}$ [106].

\section{Liver cancer}

Hepatocellular carcinoma (HCC) is a common primary liver cancer and one of the most aggressive cancers worldwide [110]. Early diagnosis has been considered as the most important factor to achieve long-term survival for $\mathrm{HCC}$ patients [111] and the emergence of novel specific and sensitive biomarkers is essential. MDK mRNA levels were higher in HCC specimens than in noncancerous tissues [112], as well as serum MDK protein levels [94] and IHC analysis showed high MDK expression in $\mathrm{HCC}$ patients [113]. Of note, the diagnostic signature approach using a combined score of MDK with other four biomarkers rather than a single one, may improve the prediction accuracy of the HCC patients [112] and the MDK levels in HCC with intra-hepatic metastasis were significantly higher than without [114]. MDK increased the diagnostic yield in alphafetoprotein (AFP)-negative HCC and had greater diagnostic performance than AFP, osteopontin, and dickkopf-1 in the diagnosis of nonalcoholic steatohepatitis-HCC, thus playing a promising role in the asymptomatic diagnosis of HCC [115].

\section{Melanoma}

Melanoma is the most deadly type of skin cancer because of its early spread via the lymphatic vessels into lymph nodes and distant organs [116]. Cutaneous melanoma is a type of cancer with an inherent potential for lymph node colonization, which is generally preceded by neolymphangiogenesis [116, 117]. The question whether tumor lymphangiogenesis occurs in human malignant melanomas of the skin and whether the extent of tumor lymphangiogenesis is related to the risk for lymph node metastasis and to patient survival has been highly challenging to answer. Analysis of the melanoma secreted proteome in cell lines and validation in clinical specimens, showed that MDK is a systematic inducer of neolymphangiogenesis that defines melanoma patient prognosis [81, 116]. More specifically, an independent series of sentinel lymph node analysis from patients with stage II-III melanoma showed that patients with high nodal MDK expression had significantly worse disease-free survival than patients with low nodal MDK expression [81, 116]. 


\section{Brain tumors}

Brain neoplasms are highly fatal and gliomas (including astrocytomas and the highest grade glioblastoma) are the most common type of primary malignant brain tumor. Gliomas are common primary brain tumors with poor outcome despite the strong treatment trials [118]. Since the clinical outcome is poor, the identification of new biomarkers for improving prognosis is highly important. Previous reports showed that increased levels of MDK expression correlate with the progression of human astrocytomas [119]. MDK overexpression was significantly correlated to poor survival outcome in high-grade stage of human gliomas [118]. Moreover, the co-expression of MDK and PTN correlates with poor survival in glioma patients, suggesting that they may be used as both early diagnostic and independent prognostic markers [120].

\section{Esophageal cancer}

The 5-year survival rate of esophageal cancer is less than $10 \%$ in developing countries, and more than $90 \%$ of these cancers are squamous cell carcinomas (ESCC) [121]. Early detection is associated with improved survival in ESCC, therefore, there is a necessity for novel biomarkers to guide therapeutic management. MDK has been found to be overexpressed in various human esophageal malignant tumors [122, 123]. The expression of MDK was correlated with poor tumor cell differentiation (poorly differentiated tumor cells-weak MDK expression) in ESCC [124]. High serum MDK levels were associated with tumor size, immunoreactivity, and poor survival in patients with esophageal cancer [125].

\section{Breast cancer}

Breast cancer is a complex genetic and highly prevalent disease and although several biomarkers have been extensively studied, only few have been approved for clinical use [126]. Different subtypes of breast cancer show diverse clinical outcome and may have different prognosis. Nowadays, there is still an urgent need to explore novel molecular targets that serve as prognostic biomarkers and novel therapeutic targets. Foremost, plasma and tissue MDK levels measurements in breast cancer patients were found abnormally elevated compared with healthy individuals $[127,128]$, suggesting that MDK is disturbed early on in the course of disease progression. Moreover, increased plasma MDK levels in combination with conventional markers (such as CA15-3, CEA, and NCC-ST435) provided significant improvement for breast cancer diagnosis [127]. Furthermore, increased MDK levels were correlated with menopausal status and nuclear grade in primary invasive breast cancer without distant metastasis [127]. Although promising, the clinical significance of MDK in the plasma of breast cancer patients needs further exploration.

\section{Ovarian cancer}

Ovarian cancer is the 8th most common cancer in women and the 2nd most common type of gynecological cancer in the world [129]. The development of more accurate and "early detection" tests for ovarian cancer are undoubtedly the top priority for reducing mortality. A prior study has confirmed the utility of both MDK and anterior gradient 2 (AGR2) proteins as plasma biomarkers for ovarian cancer and, when combined in a multianalyte panel (consisting of MDK, AGR2, and CA125), it was shown these two proteins to significantly improve the diagnostic efficiency of CA125 [130].

\section{The role of MDK as a predictive cancer biomarker in chemotherapy}

Accumulating evidence indicates that MDK plays an important role as a drug-resistance regulatory factor. For example, it was previously demonstrated that MDK protects cancer cells against cannabinoid and doxorubicin treatment [55, 131, 132]. Furthermore, MDK was overexpressed in drug-resistant gastric cancer cell sublines compared with the parental drug-sensitive ones [133]. Contrarily, other studies indicate that MDK downregulation induces cisplatin resistance in oral squamous [134] and renal carcinomas [135]. These observations collectively suggest that MDK may potentially induce either a drug-resistant or a drug-sensitive cancer cell phenotype, depending on the context.

Several studies merely focused on the effect of MDK expression in tumor microenvironment (TME) cells on chemoresistance via different mechanisms. For example, it has been shown that MDK activated the Akt signaling pathway that provides cytoprotective signals to doxorubicin [136], as opposed to the MDK-sensitized ovarian cancer cells to paclitaxel and/or cisplatin [137]. In another study, it was demonstrated that the cytotoxic effect of cisplatin on the human gastric cancer cell line AGS was attenuated by recombinant human MDK, and was promoted by suppressing MDK through downregulation of Notch pathway ligands and receptors [138]. Ovarian cancer cell lines expressing MDK levels were also used to detect drug cytotoxicity in vitro [137]; MDK could inhibit the expression of the multidrug resistance-associated protein 3 and as such, enhanced the cytotoxicity of paclitaxel and/or cisplatin [137]. MDK was also shown to have cytoprotective effect against cell-damaging effects of cisplatin, in part through the enhancement of Bcl-2 expression in Wilms' 
tumor [36]. Moreover, investigating the role of MDK in the interplay between stromal cells and tumor cells, it was found that cancer-associated fibroblasts (CAFs) in the TME contribute to high MDK levels in tumors and that CAFderived MDK can promote cisplatin resistance [139]. In another study, Hu et al. found that MDK expression causes increased efflux of chemotherapeutic drugs in lymphoblastic leukemia cells [140].

Overall, it appears that MDK may protect cancer cells from the cytotoxic effects of chemotherapy (chemoresistance), however in some cases enhance the chemosensitivity, depending on the drug/tumor type combination. It is crucial to understand the molecular mechanisms that drive the MDK-induced chemotherapeutic agent resistance and/or chemosensitivity as they may aid the introduction of new therapies in cancer.

\section{Strategies for MDK-mediated therapeutics in cancer}

A growing body of evidence, including evidence described in the current review, has demonstrated that MDK is a promising candidate as a therapeutic target for many human carcinomas [64]. MDK inhibitors including antibodies, aptamers, GAGs, peptides, and low molecular weight compounds, are currently under preclinical development [18]. MDK inhibition was found to induce apoptosis [141] and suppress tumor growth and metastasis [142]. Indeed, MDK gene knockdown by siRNA significantly induced apoptosis, while rec-MDK increased cell proliferation in osteosarcoma [142]. Along the same study, inhibition of MDK-mediated signaling by anti-MDK monoclonal antibody suppressed the in vitro and in vivo growth in osteosarcoma [142]. Moreover, (siRNA)-mediated inhibition of MDK expression and antisense MDK oligodeoxyribonucleotides had antitumor activity [143, 144].

Other trials suggested an MDK promoter-based conditionally replicative adenovirus therapy for tumors highly expressing MDK [145-147]. An oncolytic adenovirus was engineered, whose replication is under the control of the MDK promoter, to inhibit the growth of glioblastoma xenografts [18]. Interestingly, there is also a great interest in the discovery of synthesized tetrasaccharide derivatives following the GAG-related sequence GlcNAc- $\beta(1 \rightarrow 4)$-Glc$\beta(1 \rightarrow 3)$ that strongly interact with the heparin-binding growth factor MDK [148].

MDK has also demonstrated synergism with natural compounds with anticancer properties. In ovarian cancer, combined treatment of dihydroartemisinin and curcumin synergistically exhibited prominent antitumor activity via attenuation of MDK expression [149]. In another study, targeting MDK siRNA and quercetin administration synergistically reduced the cell survival, induced apoptosis and caused G1 phase cell cycle arrest more effectively than the individual therapy [150].

There are different MDK-mediated pathways that affect chemoresistsance. MDK upregulation has been linked to the failure of cancer therapies such as chemotherapy [133]. Several studies indicate the secretion and overexpression of MDK in drug-resistant cells $[55,151]$ and as such, targeting MDK could provide a new therapeutic approach for treating MDK-expressing tumors [141]. By inhibiting/blocking the MDK mode of action prior to, or during, chemotherapy may force chemoresistant cells to revert to sensitive cells and may thus provide a tremendous benefit to patients with advanced cancers not responding to conventional treatments. Interestingly, the relationship between MDK expression, tumor response and chemotherapy response is complex and may depend upon tumor type, disease etiology, and may also be stage-specific.

Overall, patient outcome can be improved with the future development of novel therapies interfering with identified MDK signaling pathways or the mechanisms of MDKmediated chemoresistance (i.e., interference of the MDKmediated expression that regulates drug efflux upstream of the p-glycoprotein and the other transporter proteins in lymphoblastic leukemia cells) [140]. Novel therapies applied with MDK inhibitors can serve in a more selective and less cytotoxic manner with maximum efficiency and without resistance and/or recurrence. In future trials we anticipate that, combined treatment of MDK inhibitors or mAbs with chemotherapeutic drugs and not single drug treatment, may cause significant tumor retardation without side effects in xenograft nude mice tumor model and clinical trials as a safe therapeutic regimen. Since mice lacking the MDK gene are viable [20, 141], targeting MDK with novel inhibitors is an attractive therapeutic approach, because its inhibition is unlikely to have systemic deleterious effects. Although further studies are needed, including identification of MDK direct targets, additional structural modification and safety validation, MDK inhibitors look promising therapeutic targets for the treatment of several cancers.

Although MDK has been suggested as a potential, novel therapeutic drug for cancer therapy, we cannot exclude the role that the tumor microenvironment may play in obfuscating therapeutic efficacy, especially in highly desmoplastic tumors [152], such as in the highly fibrotic cancers (i.e., in pancreatic cancer), in which MDK has been suggested to play a role in invasion and metastasis) [65]. Collagen accumulation in desmoplastic pancreatic cancer could be a profound obstacle for the delivery of drugs targeting MDK (i.e., MDK inhibitors or mAbs etc). Novel technologies aiming at improved drug delivery methods (i.e., nanoparticles etc) [153] will be paramount in solving these issues. 
Overall, MDK could represent a promising molecular target for cancer therapy, therefore, it is important to explore the implicated regulatory MDK-mediated mechanisms in cancer progression and metastasis.

\section{Future perspectives}

In this review we have summarized the multiple biological functions of MDK, a heparin-binding growth factor and cytokine frequently upregulated in many malignancies, strongly suggesting its involvement in cancer development and progression, and further delineating its role as a cancer biomarker and a novel therapeutic target.

We reviewed here that a large number of studies have demonstrated higher MDK expression in malignant tissues [3]. The main advantage regarding the applicability of MDK in clinical practice is that it is a soluble cytokine, which is easily measurable in the peripheral circulation, making it a relatively convenient and noninvasive biomarker [3]. Its potential role as a tumor biomarker constitutes MDK a sound target for diagnostic tests measuring circulating growth factors, and indeed, such MDK tests are currently tested in the clinic. MDK has already been shown to significantly improve detection, management and treatment of cancer, and there is significant promise for developing further MDK-based diagnostics in the future. However, there is also a prominent disadvantage in this landscape: the lack of specificity. To overcome this issue, a number of studies have combined MDK with other biomarkers (multianalyte biomarker panel), suggesting that this approach could outperform other current serum biomarkers for early detection of malignancies. In any case, large cohort analyses have not yet performed to evaluate the utility of MDK as a cancer biomarker in any of the aforementioned contexts.

The mechanism by which MDK induces tumorigenesis has been related to cancer cell proliferation, survival, antiapoptosis, angiogenesis, and EMT-regulation [22, 23]. MDK functions are mediated mainly through specific receptor binding, which triggers well-known downstream signaling pathways implicated in tumor growth and metastasis, such as the mitogen-activated protein kinase (MAPK), PI3K/Akt, and extracellular signal-regulated kinase 1/2 (ERK 1/2) [22, 23]. Importantly, melanoma metastasis was one of the highlighted topics in a recent study by Olmeda et al., describing that the top candidate mediator of melanoma lymphangiogenesis and metastasis was MDK, underscoring its potential as a therapeutic target in melanoma metastasis [81]. Moreover, MDK is an angiogenic factor that mainly promotes tumor growth and progression [25], although the exact mechanisms of MDKmediated angiogenesis need to be further elucidated. The delineation of the MDK-mediated angiogenesis mechanisms along with the development of MDK inhibitors as antiangiogenic therapeutic aspects is highly recommended.

Several studies focus merely on tumor-derived MDKmediated chemoresistance in both an autocrine- and stromal-mediated paracrine-derived manner [131, 139]. However, the role of MDK in drug resistance has remained largely elusive, underscoring the need to explore the potential MDK-mediated mechanisms underlying chemoresistance and/or chemosensitivity in order to enhance its effect and prolong patient survival.

We have also examined recent observations of MDK serving as a therapeutic target for certain human carcinomas. A better understanding of the MDK-mediated signaling pathways may open up novel therapeutic strategies for a large number of cancer subtypes. Conditional transgenic mice using CRISPR-Cas9 technology and newly identified MDK inhibitors will constitute novel and powerful tools towards this cause. An alternative therapeutic method could be the inhibition of MDK-cell surface receptors interaction with novel lead compounds. The wealth of novel small molecule inhibitors that have, or will be, successfully developed against MDK and/or its receptors, substantiates MDK as an attractive drug target in cancer.

Because of its wide expression in cancer tissues and its contribution to tumorigenesis, MDK can be considered as a tumor-shared antigen and appears to be an attractive cancer vaccine candidate. MDK-based vaccination using peptides, DNA, the whole protein, or viral vectors could be applied to patients who have a significant level of MDK in their body fluids [14].

Immune checkpoint blockade immunotherapy employs antibody targeting of specific inhibitory receptors and ligands, such as cytotoxic T-lymphocyte associated antigen 4 , programmed cell death protein 1 (PD-1), and programmed cell death ligand 1 (PD-L1) [154]. For instance one of the common immunotherapeutic drugs (Pembrolizumab) is a humanized monoclonal antibody targeting PD-1 and has been approved for the treatment of many primaries including, unresectable or metastatic melanomas [155] metastatic NSCLC [156], advanced urothelial cancer [157] and against any unresectable or metastatic solid tumor with DNA mismatch repair deficiency or a microsatellite instability-high state or colon cancer that exhibits progression under treatment (FDA approval, May 2017). Since MDK is a pan-cancer biomarker expressed in a wide range of cancer tissues, it could serve as a predictive biomarker for the likelihood of a patient responding favorably to therapy or developing toxicity, and allow for the monitoring of their therapeutic outcome. Therefore, MDK as a secreted protein could be served as a routinely available blood or urine biomarker that may have shown promise in predicting immunotherapy response. Moreover, evaluated and highly 
specific MDK monoclonal antibodies could be used in combination with the already recommended immune checkpoint inhibitors (i.e., PD-1/PD-L1) (i.e., Pembrolizumab monoclonal antibody) that may improve the therapeutic efficiency and the clinical outcome of cancer patients.

New and exciting findings in the MDK field are now beginning to emerge, however a lot is still to be achieved, and several questions remain unanswered: (i) what is the relative functional contribution of the different MDK forms in cancer progression?, (ii) are there specific MDK mutations that correlate its expression with cancer disease progression?, (iii) what type of inhibitors should we develop for compatible clinical trials and would these inhibitors be promising therapeutic targets in personalized medicine? Many challenges lie ahead before our complete understanding on the MDK-related network, contributing to MDK-driven cancer tumorigenesis and response to therapy.

\section{Compliance with ethical standards}

Conflict of interest The authors declare that they have no conflict of interest.

Publisher's note Springer Nature remains neutral with regard to jurisdictional claims in published maps and institutional affiliations.

\section{References}

1. Kadomatsu K, Tomomura M, Muramatsu T. cDNA cloning and sequencing of a new gene intensely expressed in early differentiation stages of embryonal carcinoma cells and in midgestation period of mouse embryogenesis. Biochemical biophysical Res Commun. 1988;151:1312-8.

2. Muramatsu T. Midkine and pleiotrophin: two related proteins involved in development, survival, inflammation and tumorigenesis. J Biochem. 2002;132:359-71.

3. Jones DR. Measuring midkine: the utility of midkine as a biomarker in cancer and other diseases. $\mathrm{Br} \mathrm{J}$ Pharmacol. 2014;171:2925-39.

4. Jono H, Ando Y. Midkine: a novel prognostic biomarker for cancer. Cancers. 2010;2:624-41.

5. Ikematsu S, Nakagawara A, Nakamura Y, Ohira M, Shinjo M, Kishida S, et al. Plasma midkine level is a prognostic factor for human neuroblastoma. Cancer Sci. 2008;99:2070-4.

6. Kaifi JT, Fiegel HC, Rafnsdottir SL, Aridome K, Schurr PG, Reichelt U, et al. Midkine as a prognostic marker for gastrointestinal stromal tumors. J Cancer Res Clin Oncol. 2007;133:431-5.

7. Ikematsu S, Okamoto K, Yoshida Y, Oda M, Sugano-Nagano H, Ashida K, et al. High levels of urinary midkine in various cancer patients. Biochemical Biophysical Res Commun. 2003;306:329-32.

8. Maeda S, Shinchi H, Kurahara H, Mataki Y, Noma H, Maemura $\mathrm{K}$, et al. Clinical significance of midkine expression in pancreatic head carcinoma. Br J cancer. 2007;97:405-11.

9. Muramatsu T. Midkine, a heparin-binding cytokine with multiple roles in development, repair and diseases. Proc Jpn Acad Ser B, Phys Biol Sci. 2010;86:410-25.
10. Inazumi T, Tajima S, Nishikawa T, Kadomatsu K, Muramatsu H, Muramatsu T. Expression of the retinoid-inducible polypeptide, midkine, in human epidermal keratinocytes. Arch Dermatol Res. 1997;289:471-5.

11. Nordin SL, Jovic S, Kurut A, Andersson C, Gela A, Bjartell A, et al. High expression of midkine in the airways of patients with cystic fibrosis. Am J Respiratory Cell Mol Biol. 2013;49:935-42.

12. Cohen S, Shoshana OY, Zelman-Toister E, Maharshak N, Binsky-Ehrenreich I, Gordin M, et al. The cytokine midkine and its receptor RPTPzeta regulate B cell survival in a pathway induced by CD74. J Immunol. 2012;188:259-69.

13. Hovanessian AG. Midkine, a cytokine that inhibits HIV infection by binding to the cell surface expressed nucleolin. Cell Res. 2006;16:174-81.

14. Kerzerho J, Adotevi O, Castelli FA, Dosset M, Bernardeau K, Szely N, et al. The angiogenic growth factor and biomarker midkine is a tumor-shared antigen. J Immunol. 2010;185:418-23.

15. Lee SH, Suh HN, Lee YJ, Seo BN, Ha JW, Han HJ. Midkine prevented hypoxic injury of mouse embryonic stem cells through activation of Akt and HIF-1alpha via low-density lipoprotein receptor-related protein-1. J Cell Physiol. 2012;227:1731-9.

16. Kadomatsu K, Huang RP, Suganuma T, Murata F, Muramatsu T. A retinoic acid responsive gene $\mathrm{MK}$ found in the teratocarcinoma system is expressed in spatially and temporally controlled manner during mouse embryogenesis. J Cell Biol. 1990;110:607-16.

17. Mitsiadis TA, Salmivirta M, Muramatsu T, Muramatsu H, Rauvala H, Lehtonen E, et al. Expression of the heparin-binding cytokines, midkine (MK) and HB-GAM (pleiotrophin) is associated with epithelial-mesenchymal interactions during fetal development and organogenesis. Development. 1995;121:37-51.

18. Muramatsu T. Midkine: a promising molecule for drug development to treat diseases of the central nervous system. Curr Pharm Des. 2011;17:410-23.

19. Nakamura E, Kadomatsu K, Yuasa S, Muramatsu H, Mamiya T, Nabeshima T, et al. Disruption of the midkine gene (Mdk) resulted in altered expression of a calcium binding protein in the hippocampus of infant mice and their abnormal behaviour. Genes Cells. 1998;3:811-22.

20. Zou P, Muramatsu H, Sone M, Hayashi H, Nakashima T, Muramatsu T. Mice doubly deficient in the midkine and pleiotrophin genes exhibit deficits in the expression of beta-tectorin gene and in auditory response. Lab Investig. 2006;86:645-53.

21. Ohgake S, Shimizu E, Hashimoto K, Okamura N, Koike K, Koizumi $\mathrm{H}$, et al. Dopaminergic hypofunctions and prepulse inhibition deficits in mice lacking midkine. Prog NeuroPsychopharmacol Biol Psychiatry. 2009;33:541-6.

22. Muramatsu T. Structure and function of midkine as the basis of its pharmacological effects. Br J Pharmacol. 2014;171:814-26.

23. Kadomatsu K, Kishida S, Tsubota S. The heparin-binding growth factor midkine: the biological activities and candidate receptors. J Biochem. 2013;153:511-21.

24. Erguven M, Bilir A, Yazihan N, Ermis E, Sabanci A, Aktas E, et al. Decreased therapeutic effects of noscapine combined with imatinib mesylate on human glioblastoma in vitro and the effect of midkine. Cancer Cell Int. 2011;11:18.

25. Choudhuri R, Zhang HT, Donnini S, Ziche M, Bicknell R. An angiogenic role for the neurokines midkine and pleiotrophin in tumorigenesis. Cancer Res. 1997;57:1814-9.

26. Muramatsu H, Muramatsu T. Purification of recombinant midkine and examination of its biological activities: functional comparison of new heparin binding factors. Biochemical Biophysical Res Commun. 1991;177:652-8.

27. Wang Q, Huang Y, Ni Y, Wang H, Hou Y. siRNA targeting midkine inhibits gastric cancer cells growth and induces 
apoptosis involved caspase-3,8,9 activation and mitochondrial depolarization. J Biomed Sci. 2007;14:783-95.

28. Kerzerho J, Schneider A, Favry E, Castelli FA, Maillere B. The signal peptide of the tumor-shared antigen midkine hosts CD4+ T cell epitopes. J Biol Chem. 2013;288:13370-7.

29. Lu Y, Yan B, Guo H, Qiu L, Sun X, Wang X, et al. Effect of midkine on gemcitabine resistance in biliary tract cancer. Int $\mathrm{J}$ Mol Med. 2018;41:2003-11.

30. Matsubara S, Tomomura M, Kadomatsu K, Muramatsu T. Structure of a retinoic acid-responsive gene, MK, which is transiently activated during the differentiation of embryonal carcinoma cells and the mid-gestation period of mouse embryogenesis. J Biol Chem. 1990;265:9441-3.

31. Kaname T, Kuwano A, Murano I, Uehara K, Muramatsu T, Kajii T. Midkine gene (MDK), a gene for prenatal differentiation and neuroregulation, maps to band $11 \mathrm{p} 11.2$ by fluorescence in situ hybridization. Genomics. 1993;17:514-5.

32. Murasugi A, Tohma-Aiba Y. Production of native recombinant human midkine in the yeast, Pichia pastoris. Protein Expr Purif. 2003;27:244-52.

33. Pedraza C, Matsubara S, Muramatsu T. A retinoic acidresponsive element in human midkine gene. $\mathrm{J}$ Biochem. 1995; 117:845-9.

34. Reynolds P, Mucenski M, Le Cras T, Nichols W, Whitsett J. Midkine is regulated by hypoxia and causes pulmonary vascular remodeling. J Biol Chem. 2004;279:37124-32.

35. Adachi Y, Matsubara S, Pedraza C, Ozawa M, Tsutsui J, Takamatsu $\mathrm{H}$, et al. Midkine as a novel target gene for the Wilms' tumor suppressor gene (WT1). Oncogene. 1996; 13:2197-203.

36. Qi M, Ikematsu S, Ichihara-Tanaka K, Sakuma S, Muramatsu T, Kadomatsu K. Midkine rescues Wilms' tumor cells from cisplatin-induced apoptosis: regulation of Bcl-2 expression by Midkine. J Biochem. 2000;127:269-77.

37. Kaplan F, Comber J, Sladek R, Hudson TJ, Muglia LJ, Macrae $\mathrm{T}$, et al. The growth factor midkine is modulated by both glucocorticoid and retinoid in fetal lung development. Am J Respiratory Cell Mol Biol. 2003;28:33-41.

38. Tao P, Xu D, Lin S, Ouyang GL, Chang Y, Chen Q, et al. Abnormal expression, highly efficient detection and novel truncations of midkine in human tumors, cancers and cell lines. Cancer Lett. 2007;253:60-7.

39. Paul S, Mitsumoto T, Asano Y, Kato S, Kato M, Shinozawa T. Detection of truncated midkine in Wilms' tumor by a monoclonal antibody against human recombinant truncated midkine. Cancer Lett. 2001;163:245-51.

40. Novotny WF, Maffi T, Mehta RL, Milner PG. Identification of novel heparin-releasable proteins, as well as the cytokines midkine and pleiotrophin, in human postheparin plasma. Arteriosclerosis Thromb. 1993;13:1798-805.

41. Fabri L, Maruta H, Muramatsu H, Muramatsu T, Simpson RJ, Burgess AW, et al. Structural characterisation of native and recombinant forms of the neurotrophic cytokine MK. J Chromatogr. 1993;646:213-25.

42. Matsuda Y, Talukder AH, Ishihara M, Hara S, Yoshida K, Muramatsu $\mathrm{T}$, et al. Limited proteolysis by chymotrypsin of midkine and inhibition by heparin binding. Biochemical Biophysical Res Commun. 1996;228:176-81.

43. Kadomatsu K, Muramatsu T. Midkine and pleiotrophin in neural development and cancer. Cancer Lett. 2004;204:127-43.

44. Maeda N, Ichihara-Tanaka K, Kimura T, Kadomatsu K, Muramatsu T, Noda M. A receptor-like protein-tyrosine phosphatase PTPzeta/RPTPbeta binds a heparin-binding growth factor midkine. Involvement of arginine 78 of midkine in the high affinity binding to PTPzeta. J Biol Chem. 1999;274:12474-9.
45. Kurosawa N, Chen GY, Kadomatsu K, Ikematsu S, Sakuma S, Muramatsu T. Glypican-2 binds to midkine: the role of glypican2 in neuronal cell adhesion and neurite outgrowth. Glycoconj J. 2001;18:499-507.

46. Muramatsu H, Zou K, Sakaguchi N, Ikematsu S, Sakuma S, Muramatsu T. LDL receptor-related protein as a component of the midkine receptor. Biochemical Biophysical Res Commun. 2000;270:936-41.

47. Muramatsu H, Zou P, Suzuki H, Oda Y, Chen GY, Sakaguchi N, et al. alpha4beta1- and alpha6beta1-integrins are functional receptors for midkine, a heparin-binding growth factor. J Cell Sci. 2004;117:5405-15.

48. Tsutsui J, Kadomatsu K, Matsubara S, Nakagawara A, Hamanoue M, Takao S, et al. A new family of heparin-binding growth/differentiation factors: increased midkine expression in Wilms' tumor and other human carcinomas. Cancer Res. 1993;53:1281-5.

49. Muramatsu $H$, Shirahama $H$, Yonezawa $S$, Maruta $H$, Muramatsu T. Midkine, a retinoic acid-inducible growth/differentiation factor: immunochemical evidence for the function and distribution. Dev Biol. 1993;159:392-402.

50. Owada K, Sanjyo N, Kobayashi T, Kamata T, Mizusawa H, Muramatsu H, et al. Midkine inhibits apoptosis via extracellular signal regulated kinase (ERK) activation in PC12 cells. J Med Dent Sci. 1999;46:45-51.

51. Qi M, Ikematsu S, Maeda N, Ichihara-Tanaka K, Sakuma S, Noda $\mathrm{M}$, et al. Haptotactic migration induced by midkine. Involvement of protein-tyrosine phosphatase zeta. Mitogenactivated protein kinase, and phosphatidylinositol 3-kinase. J Biol Chem. 2001;276:15868-75.

52. Hanahan D, Weinberg RA. Hallmarks of cancer: the next generation. Cell. 2011;144:646-74.

53. Lorente M, Torres S, Salazar M, Carracedo A, Hernandez-Tiedra S, Rodriguez-Fornes F, et al. Stimulation of ALK by the growth factor midkine renders glioma cells resistant to autophagymediated cell death. Autophagy. 2011;7:1071-3.

54. Stoica GE, Kuo A, Powers C, Bowden ET, Sale EB, Riegel AT, et al. Midkine binds to anaplastic lymphoma kinase (ALK) and acts as a growth factor for different cell types. J Biol Chem. 2002;277:35990-8.

55. Lorente M, Torres S, Salazar M, Carracedo A, Hernandez-Tiedra $\mathrm{S}$, Rodriguez-Fornes $\mathrm{F}$, et al. Stimulation of the midkine/ALK axis renders glioma cells resistant to cannabinoid antitumoral action. Cell Death Differ. 2011;18:959-73.

56. Cohen S, Shachar I. Midkine as a regulator of B cell survival in health and disease. Br J Pharmacol. 2014;171:888-95.

57. Gustavsson H, Jennbacken K, Welen K, Damber JE. Altered expression of genes regulating angiogenesis in experimental androgen-independent prostate cancer. Prostate. 2008;68:161-70.

58. Muramaki M, Miyake H, Hara I, Kamidono S. Introduction of midkine gene into human bladder cancer cells enhances their malignant phenotype but increases their sensitivity to antiangiogenic therapy. Clin Cancer Res. 2003;9:5152-60.

59. Mashour GA, Ratner N, Khan GA, Wang HL, Martuza RL, Kurtz A. The angiogenic factor midkine is aberrantly expressed in NF1-deficient Schwann cells and is a mitogen for neurofibroma-derived cells. Oncogene. 2001;20:97-105.

60. Dai LC, Wang X, Yao X, Lu YL, Ping JL, He JF. Antisense oligonucleotide targeting midkine suppresses in vivo angiogenesis. World J Gastroenterol. 2007;13:1208-13.

61. Lautz T, Lasch M, Borgolte J, Troidl K, Pagel JI, CaballeroMartinez A, et al. Midkine controls arteriogenesis by regulating the bioavailability of vascular endothelial growth factor A and the expression of nitric oxide synthase 1 and 3. EBioMedicine. 2018;27:237-46. 
62. Weckbach LT, Groesser L, Borgolte J, Pagel JI, Pogoda F, Schymeinsky $\mathrm{J}$, et al. Midkine acts as proangiogenic cytokine in hypoxia-induced angiogenesis. Am J Physiol Heart Circ Physiol. 2012;303:H429-38.

63. Muramatsu T, Kadomatsu K. Midkine: an emerging target of drug development for treatment of multiple diseases. $\mathrm{Br} \mathrm{J}$ Pharmacol. 2014;171:811-3.

64. Kishida S, Kadomatsu K. Involvement of midkine in neuroblastoma tumourigenesis. Br J Pharmacol. 2014;171:896-904.

65. Grupp K, Melling N, Bogoevska V, Reeh M, Uzunoglu FG, El Gammal AT, et al. Expression of ICAM-1, E-cadherin, periostin and midkine in metastases of pancreatic ductal adenocarcinomas. Exp Mol Pathol. 2018;104:109-13.

66. Katsuno Y, Lamouille S, Derynck R. TGF-beta signaling and epithelial-mesenchymal transition in cancer progression. Curr Opin Oncol. 2013;25:76-84.

67. Papageorgis P. TGFbeta signaling in tumor initiation, epithelialto-mesenchymal transition, and metastasis. J Oncol. 2015; 2015:587193.

68. Sandra F, Harada H, Nakamura N, Ohishi M. Midkine induced growth of ameloblastoma through MAPK and Akt pathways. Oral Oncol. 2004;40:274-80.

69. Ohuchida T, Okamoto K, Akahane K, Higure A, Todoroki H, Abe Y, et al. Midkine protects hepatocellular carcinoma cells against TRAIL-mediated apoptosis through down-regulation of caspase-3 activity. Cancer. 2004;100:2430-6.

70. Zhao G, Nie Y, Lv M, He L, Wang T, Hou Y. ERbeta-mediated estradiol enhances epithelial mesenchymal transition of lung adenocarcinoma through increasing transcription of midkine. Mol Endocrinol. 2012;26:1304-15.

71. Liedert A, Mattausch L, Rontgen V, Blakytny R, Vogele D, Pahl $\mathrm{M}$, et al. Midkine-deficiency increases the anabolic response of cortical bone to mechanical loading. Bone. 2011;48:945-51.

72. Meng K, Rodriguez-Pena A, Dimitrov T, Chen W, Yamin M, Noda M, et al. Pleiotrophin signals increased tyrosine phosphorylation of beta beta-catenin through inactivation of the intrinsic catalytic activity of the receptor-type protein tyrosine phosphatase beta/zeta. Proc Natl Acad Sci USA. 2000; 97:2603-8.

73. Tang SL, Gao YL, Chen XB. Wnt/beta-catenin up-regulates Midkine expression in glioma cells. Int $\mathrm{J}$ Clin Exp Med. 2015;8:12644-9.

74. Gungor C, Zander H, Effenberger KE, Vashist YK, Kalinina T, Izbicki JR, et al. Notch signaling activated by replication stressinduced expression of midkine drives epithelial-mesenchymal transition and chemoresistance in pancreatic cancer. Cancer Res. 2011;71:5009-19.

75. Huang Y, Hoque MO, Wu F, Trink B, Sidransky D, Ratovitski EA. Midkine induces epithelial-mesenchymal transition through Notch2/Jak2-Stat3 signaling in human keratinocytes. Cell Cycle. 2008;7:1613-22.

76. Filippou PS, Farkona S, Brinc D, Yu Y, Prassas I, Diamandis EP. Biochemical and functional characterization of the human tissue kallikrein 9. Biochemical J. 2017;474:2417-33.

77. Yu Y, Prassas I, Dimitromanolakis A, Diamandis EP. Novel biological substrates of human kallikrein 7 identified through degradomics. J Biol Chem. 2015;290:17762-75.

78. Filippou PS, Karagiannis GS, Musrap N, Diamandis EP. Kallikrein-related peptidases (KLKs) and the hallmarks of cancer. Crit Rev Clin Lab Sci. 2016;53:277-91.

79. Haddada M, Draoui H, Deschamps L, Walker F, Delaunay T, Brattsand M, et al. Kallikrein-related peptidase 7 overexpression in melanoma cells modulates cell adhesion leading to a malignant phenotype. Biol Chem. 2018;399:1099-105.

80. Geng X, Liu Y, Diersch S, Kotzsch M, Grill S, Weichert W, et al. Clinical relevance of kallikrein-related peptidase 9, 10, 11, and 15 mRNA expression in advanced high-grade serous ovarian cancer. PloS ONE. 2017;12:e0186847.

81. Olmeda D, Cerezo-Wallis D, Riveiro-Falkenbach E, Pennacchi PC, Contreras-Alcalde M, Ibarz N, et al. Whole-body imaging of lymphovascular niches identifies pre-metastatic roles of midkine. Nature. 2017;546:676-80.

82. Mitchell MS, Lund TA, Sewell AK, Marincola FM, Paul E, Schroder $\mathrm{K}$, et al. The cytotoxic $\mathrm{T}$ cell response to peptide analogs of the HLA-A*0201-restricted MUC1 signal sequence epitope, M1.2. Cancer Immunol Immunother. 2007;56:287-301.

83. Fernandez-Calle R, Vicente-Rodriguez M, Gramage E, de la Torre-Ortiz C, Perez-Garcia C, Ramos MP, et al. Endogenous pleiotrophin and midkine regulate LPS-induced glial responses. Neurosci Lett. 2018;662:213-8.

84. Gela A, Jovic S, Nordin SL, Egesten A. Midkine in host defence. Br J Pharmacol. 2014;171:859-69.

85. Weckbach LT, Muramatsu T, Walzog B. Midkine in inflammation. TheScientificWorldJournal. 2011;11:2491-505.

86. Tazzyman S, Lewis CE, Murdoch C. Neutrophils: key mediators of tumour angiogenesis. Int J Exp Pathol. 2009;90:222-31.

87. Weckbach LT, Gola A, Winkelmann M, Jakob SM, Groesser L, Borgolte J, et al. The cytokine midkine supports neutrophil trafficking during acute inflammation by promoting adhesion via beta2 integrins (CD11/CD18). Blood. 2014;123:1887-96.

88. Haffner-Luntzer M, Heilmann A, Rapp AE, Beie S, Schinke T, Amling $\mathrm{M}$, et al. Midkine-deficiency delays chondrogenesis during the early phase of fracture healing in mice. PloS ONE. 2014;9:e116282.

89. Fischer V, Kalbitz M, Muller-Graf F, Gebhard F, Ignatius A, Liedert A et al. Influence of menopause on inflammatory cytokines during murine and human bone fracture healing. Int $\mathrm{J}$ Mol Sci. 2018;19:2070. https://doi.org/10.3390/ijms19072070.

90. Garver RI Jr., Chan CS, Milner PG. Reciprocal expression of pleiotrophin and midkine in normal versus malignant lung tissues. Am J Respir Cell Mol Biol. 1993;9:463-6.

91. Garver RI Jr., Radford DM, Donis-Keller H, Wick MR, Milner PG. Midkine and pleiotrophin expression in normal and malignant breast tissue. Cancer. 1994;74:1584-90.

92. Konishi N, Nakamura M, Nakaoka S, Hiasa Y, Cho M, Uemura $\mathrm{H}$, et al. Immunohistochemical analysis of midkine expression in human prostate carcinoma. Oncology. 1999;57:253-7.

93. Ye C, Qi M, Fan QW, Ito K, Akiyama S, Kasai Y, et al. Expression of midkine in the early stage of carcinogenesis in human colorectal cancer. Br J Cancer. 1999;79:179-84.

94. Muramatsu H, Song XJ, Koide N, Hada H, Tsuji T, Kadomatsu $\mathrm{K}$, et al. Enzyme-linked immunoassay for midkine, and its application to evaluation of midkine levels in developing mouse brain and sera from patients with hepatocellular carcinomas. J Biochem. 1996;119:1171-5.

95. Ikematsu S, Yano A, Aridome K, Kikuchi M, Kumai H, Nagano $\mathrm{H}$, et al. Serum midkine levels are increased in patients with various types of carcinomas. Br J Cancer. 2000;83:701-6.

96. Torres A, Pac-Sosinska M, Wiktor K, Paszkowski T, Maciejewski R, Torres K. CD44, TGM2 and EpCAM as novel plasma markers in endometrial cancer diagnosis. BMC Cancer. 2019;19:401.

97. Jing X, Cui X, Liang H, Hao C, Han C. Diagnostic accuracy of ELISA for detecting serum Midkine in cancer patients. PloS ONE. 2017;12:e0180511.

98. Zhang L, Song X, Shao Y, Wu C, Jiang J. Prognostic value of Midkine expression in patients with solid tumors: a systematic review and meta-analysis. Oncotarget. 2018;9:24821-9.

99. Gungor C, Hofmann BT, Wolters-Eisfeld G, Bockhorn M. Pancreatic cancer. Br J Pharmacol. 2014;171:849-58.

100. Ohhashi S, Ohuchida K, Mizumoto K, Egami T, Yu J, Cui L, et al. Midkine mRNA is overexpressed in pancreatic cancer. Dig Dis Sci. 2009;54:811-5. 
101. Rawnaq T, Dietrich L, Wolters-Eisfeld G, Uzunoglu FG, Vashist YK, Bachmann $\mathrm{K}$, et al. The multifunctional growth factor midkine promotes proliferation and migration in pancreatic cancer. Mol Cancer Res. 2014;12:670-80.

102. Jemal A, Bray F, Center MM, Ferlay J, Ward E, Forman D. Global cancer statistics. Cancer J Clin. 2011;61:69-90.

103. Yuan K, Chen Z, Li W, Gao CE, Li G, Guo G, et al. MDK protein overexpression correlates with the malignant status and prognosis of non-small cell lung cancer. Arch Med Res. $2015 ; 46: 635-41$.

104. Xia X, Lu JJ, Zhang SS, Su CH, Luo HH. Midkine is a serum and urinary biomarker for the detection and prognosis of nonsmall cell lung cancer. Oncotarget. 2016;7:87462-72.

105. Torre LA, Bray F, Siegel RL, Ferlay J, Lortet-Tieulent J, Jemal A. Global cancer statistics, 2012. Cancer J Clin. 2015;65:87-108.

106. Vu Van D, Heberling U, Wirth MP, Fuessel S. Validation of the diagnostic utility of urinary midkine for the detection of bladder cancer. Oncol Lett. 2016;12:3143-52.

107. O'Brien T, Cranston D, Fuggle S, Bicknell R, Harris AL. The angiogenic factor midkine is expressed in bladder cancer, and overexpression correlates with a poor outcome in patients with invasive cancers. Cancer Res. 1996;56:2515-8.

108. Shimwell NJ, Bryan RT, Wei W, James ND, Cheng KK, Zeegers MP, et al. Combined proteome and transcriptome analyses for the discovery of urinary biomarkers for urothelial carcinoma. $\mathrm{Br}$ J Cancer. 2013;108:1854-61.

109. Soukup V, Kalousova M, Capoun O, Sobotka R, Breyl Z, Pesl $\mathrm{M}$, et al. Panel of urinary diagnostic markers for non-invasive detection of primary and recurrent urothelial urinary bladder carcinoma. Urol Int. 2015;95:56-64.

110. Parkin DM, Bray F, Ferlay J, Pisani P. Global cancer statistics, 2002. Cancer J Clinicians. 2005;55:74-108.

111. Poon RT, Fan ST, Lo CM, Liu CL, Wong J. Long-term survival and pattern of recurrence after resection of small hepatocellular carcinoma in patients with preserved liver function: implications for a strategy of salvage transplantation. Ann Surg. 2002;235:373-82.

112. Jia HL, Ye QH, Qin LX, Budhu A, Forgues M, Chen Y, et al. Gene expression profiling reveals potential biomarkers of human hepatocellular carcinoma. Clin Cancer Res. 2007;13:1133-9.

113. Kato M, Shinozawa T, Kato S, Awaya A, Terada T. Increased midkine expression in hepatocellular carcinoma. Arch Pathol Lab Med. 2000;124:848-52.

114. Yin Z, Luo X, Kang X, Wu Z, Qian H, Wu M. [Correlation between midkine protein overexpression and intrahepatic metastasis in hepatocellular carcinoma]. Zhonghua zhong liu za zhi [Chin J Oncol]. 2002;24:27-9.

115. Vongsuvanh R, van der Poorten D, Iseli T, Strasser SI, McCaughan GW, George J. Midkine increases diagnostic yield in afp negative and NASH-related hepatocellular carcinoma. PloS ONE. 2016;11:e0155800.

116. Karaman S, Alitalo K. Midkine and melanoma metastasis: a malevolent mix. Dev Cell. 2017;42:205-7.

117. Zheng W, Aspelund A, Alitalo K. Lymphangiogenic factors, mechanisms, and applications. J Clin Investig. 2014;124:878-87.

118. Cheng YP, Lin C, Lin PY, Cheng CY, Ma HI, Chen CM, et al. Midkine expression in high grade gliomas: Correlation of this novel marker with proliferation and survival in human gliomas. Surg Neurol Int. 2014;5:78.

119. Mishima K, Asai A, Kadomatsu K, Ino Y, Nomura K, Narita Y, et al. Increased expression of midkine during the progression of human astrocytomas. Neurosci Lett. 1997;233:29-32.

120. Ma J, Lang B, Wang X, Wang L, Dong Y, Hu H. Co-expression of midkine and pleiotrophin predicts poor survival in human glioma. J Clin Neurosci. 2014;21:1885-90.
121. Couch G, Redman JE, Wernisch L, Newton R, Malhotra S, Dawsey SM, et al. The Discovery and Validation of Biomarkers for the Diagnosis of Esophageal Squamous Dysplasia and Squamous Cell Carcinoma. Cancer Prev Res. 2016;9:558-66.

122. Aridome K, Tsutsui J, Takao S, Kadomatsu K, Ozawa M, Aikou $\mathrm{T}$, et al. Increased midkine gene expression in human gastrointestinal cancers. Jpn J Cancer Res. 1995;86:655-61.

123. Miyauchi M, Shimada H, Kadomatsu K, Muramatsu T, Matsubara $\mathrm{S}$, Ikematsu $\mathrm{S}$, et al. Frequent expression of midkine gene in esophageal cancer suggests a potential usage of its promoter for suicide gene therapy. Jpn J cancer Res. 1999;90:469-75.

124. Ren YJ, Zhang QY. Expression of midkine and its clinical significance in esophageal squamous cell carcinoma. World $\mathrm{J}$ Gastroenterol. 2006;12:2006-10.

125. Shimada H, Nabeya Y, Tagawa M, Okazumi S, Matsubara H, Kadomatsu K, et al. Preoperative serum midkine concentration is a prognostic marker for esophageal squamous cell carcinoma. Cancer Sci. 2003;94:628-32.

126. Rakha EA, Reis-Filho JS, Ellis IO. Combinatorial biomarker expression in breast cancer. Breast Cancer Res Treat. 2010;120:293-308.

127. Ibusuki M, Fujimori H, Yamamoto Y, Ota K, Ueda M, Shinriki $\mathrm{S}$, et al. Midkine in plasma as a novel breast cancer marker. Cancer Sci. 2009;100:1735-9.

128. Miyashiro I, Kaname T, Shin E, Wakasugi E, Monden T, Takatsuka $\mathrm{Y}$, et al. Midkine expression in human breast cancers: expression of truncated form. Breast Cancer Res Treat. 1997;43:1-6.

129. Paley PJ. Ovarian cancer screening: are we making any progress? Curr Opin Oncol. 2001;13:399-402.

130. Rice GE, Edgell TA, Autelitano DJ. Evaluation of midkine and anterior gradient 2 in a multimarker panel for the detection of ovarian cancer. J Exp Clin cancer Res. 2010;29:62.

131. Chu F, Naiditch JA, Clark S, Qiu YY, Zheng X, Lautz TB, et al. Midkine mediates intercellular crosstalk between drug-resistant and drug-sensitive neuroblastoma cells in vitro and in vivo. ISRN Oncol. 2013;2013:518637.

132. Xu YY, Mao XY, Song YX, Zhao F, Wang ZN, Zhang WX, et al. Midkine confers adriamycin resistance in human gastric cancer cells. Tumour Biol. 2012;33:1543-8.

133. Kang HC, Kim IJ, Park JH, Shin Y, Ku JL, Jung MS, et al. Identification of genes with differential expression in acquired drug-resistant gastric cancer cells using high-density oligonucleotide microarrays. Clin Cancer Res. 2004;10:272-84.

134. Ota T, Jono H, Ota K, Shinriki S, Ueda M, Sueyoshi T, et al. Downregulation of midkine induces cisplatin resistance in human oral squamous cell carcinoma. Oncol Rep. 2012;27:1674-80.

135. Kawai H, Sato W, Yuzawa Y, Kosugi T, Matsuo S, Takei Y, et al. Lack of the growth factor midkine enhances survival against cisplatin-induced renal damage. Am J Pathol. 2004; 165:1603-12.

136. Rebbaa A, Chou PM, Mirkin BL. Factors secreted by human neuroblastoma mediated doxorubicin resistance by activating STAT3 and inhibiting apoptosis. Mol Med. 2001;7:393-400.

137. Wu X, Zhi X, Ji M, Wang Q, Li Y, Xie J, et al. Midkine as a potential diagnostic marker in epithelial ovarian cancer for cisplatin/paclitaxel combination clinical therapy. Am J Cancer Res. 2015;5:629-38.

138. Tian W, Shen J, Chen W. Suppression of midkine gene promotes the antitumoral effect of cisplatin on human gastric cancer cell line AGS in vitro and in vivo via the modulation of Notch signaling pathway. Oncol Rep. 2017;38:745-54.

139. Zhang D, Ding L, Li Y, Ren J, Shi G, Wang Y, et al. Midkine derived from cancer-associated fibroblasts promotes cisplatinresistance via up-regulation of the expression of lncRNA ANRIL in tumour cells. Sci Rep. 2017;7:16231. 
140. Hu R, Yan Y, Li Q, Lin Y, Jin W, Li H, et al. Increased drug efflux along with midkine gene high expression in childhood Blineage acute lymphoblastic leukemia cells. Int J Hematol. 2010;92:105-10.

141. Hao H, Maeda Y, Fukazawa T, Yamatsuji T, Takaoka M, Bao $\mathrm{XH}$, et al. Inhibition of the growth factor MDK/midkine by a novel small molecule compound to treat non-small cell lung cancer. PloS ONE. 2013;8:e71093.

142. Sueyoshi T, Jono H, Shinriki S, Ota K, Ota T, Tasaki M, et al. Therapeutic approaches targeting midkine suppress tumor growth and lung metastasis in osteosarcoma. Cancer Lett. 2012;316:23-30.

143. Takei Y, Kadomatsu K, Itoh H, Sato W, Nakazawa K, Kubota S, et al. 5'-,3'-inverted thymidine-modified antisense oligodeoxynucleotide targeting midkine. Its design and application for cancer therapy. J Biol Chem. 2002;277:23800-6.

144. Jin Z, Lahat G, Korchin B, Nguyen T, Zhu QS, Wang X, et al. Midkine enhances soft-tissue sarcoma growth: a possible novel therapeutic target. Clin Cancer Res. 2008;14:5033-42.

145. Toyoda E, Doi R, Kami K, Mori T, Ito D, Koizumi M, et al. Midkine promoter-based conditionally replicative adenovirus therapy for midkine-expressing human pancreatic cancer. J Exp Clin Cancer Res. 2008;27:30.

146. Kohno S, Nakagawa K, Hamada K, Harada H, Yamasaki K, Hashimoto $\mathrm{K}$, et al. Midkine promoter-based conditionally replicative adenovirus for malignant glioma therapy. Oncol Rep. 2004;12:73-8.

147. Yu L, Hamada K, Namba M, Kadomatsu K, Muramatsu T, Matsubara $\mathrm{S}$, et al. Midkine promoter-driven suicide gene expression and -mediated adenovirus replication produced cytotoxic effects to immortalised and tumour cells. Eur J Cancer. 2004;40:1787-94.
148. Maza S, Gandia-Aguado N, de Paz JL, Nieto PM. Fluorous-tag assisted synthesis of a glycosaminoglycan mimetic tetrasaccharide as a high-affinity FGF-2 and midkine ligand. Bioorg Med Chem. 2018;26:1076-85.

149. Zhao J, Pan Y, Li X, Zhang X, Xue Y, Wang T, et al. Dihydroartemisinin and Curcumin Synergistically Induce Apoptosis in SKOV3 Cells Via Upregulation of MiR-124 Targeting Midkine. Cell Physiol Biochem. 2017;43:589-601.

150. Erdogan S, Doganlar ZB, Doganlar O, Turkekul K, Serttas R. Inhibition of midkine suppresses prostate cancer CD133(+) stem cell growth and migration. Am J Med Sci. 2017;354:299-309.

151. Mirkin BL, Clark S, Zheng X, Chu F, White BD, Greene M, et al. Identification of midkine as a mediator for intercellular transfer of drug resistance. Oncogene. 2005;24:4965-74.

152. Olive KP. Stroma, stroma everywhere (far more than you think). Clin Cancer Res. 2015;21:3366-8.

153. Raavé R, van Kuppevelt TH, Daamen WF. Chemotherapeutic drug delivery by tumoral extracellular matrix targeting. J Controll Release. 2018;274:1-8.

154. Music M, Prassas I, Diamandis EP. Optimizing cancer immunotherapy: Is it time for personalized predictive biomarkers? Crit Rev Clin Lab Sci. 2018;55:466-79.

155. Robert C, Schachter J, Long GV, Arance A, Grob JJ, Mortier L, et al. Pembrolizumab versus Ipilimumab in Advanced Melanoma. N. Engl J Med. 2015;372:2521-32.

156. Herbst RS, Baas P, Kim DW, Felip E, Perez-Gracia JL, Han JY, et al. Pembrolizumab versus docetaxel for previously treated, PDL1-positive, advanced non-small-cell lung cancer (KEYNOTE010): a randomised controlled trial. Lancet. 2016;387:1540-50.

157. Bellmunt J, de Wit R, Vaughn DJ, Fradet Y, Lee JL, Fong L, et al. Pembrolizumab as second-line therapy for advanced urothelial carcinoma. N. Engl J Med. 2017;376:1015-26. 